\title{
Reply to Letter to Editor: Management of Suprahepatic Inferior Vena Cava Obstruction
}

\author{
Fahrettin Kucukay ${ }^{1}$
}

Received: 27 July 2016/Accepted: 1 August 2016/Published online: 8 August 2016

(C) Springer Science+Business Media New York and the Cardiovascular and Interventional Radiological Society of Europe (CIRSE) 2016

To the Editor,

We thank the author for his subtle reading and interest in our work. We agree with the author's decision about "the management of high obstruction of IVC is peculiar and substantially different from that of canonical BCS." The author stated that some serious complications including rupture of the vessel were observed during PTA for the MOVC previously but, as we performed in our cohort, we advise gradual consecutive small- to large-sized balloon usage for PTA. Other bail-out methods including surgery and liver transplantation for the treatment of high MOVC that is unresponsive to PTA or stenting must be discussed in the future.

Compliance with Ethical Standards

Conflict of Interest The author has nothing to disclose.

Formal Consent For this type of study, formal consent is not required.

Informed Consent Informed consent does not apply.

Fahrettin Kucukay

fkucukay@hotmail.com

1 Department of Interventional Radiology, Faculty of Medicine, Eskisehir Osmangazi University, Eskişehir, Turkey 